\title{
The Relationship Between Salesmen's Emotional Intelligence and Sales Skills in In-Person Sales (Case Study: Salesmen of Commercial Complexes in the Third Municipality District of Bandar Abbas City)
}

\author{
Homayoun Pegah ${ }^{1}$ \\ ${ }^{1}$ MBA Major in Marketing, School of Management \& Accounting, Islamic Azad University of Bandar Abbas \\ Branch, Bandar Abbas City, Iran \\ Correspondence: Homayoun Pegah, MBA Major in Marketing, School of Management \& Accounting, Islamic \\ Azad University of Bandar Abbas Branch, Bandar Abbas City, Iran. E-mail: Bmrpegah@icloud.com
}

Received: March 10, 2020 Accepted: April 16, 2020 Online Published: April 27, 2020

doi:10.5539/ijms.v12n2p62 URL: https://doi.org/10.5539/ijms.v12n2p62

\begin{abstract}
The research statistical population was unlimited and included all salesmen in the stores of four large and famous commercial complexes in the Bandar Abbas City at Hormozgan Province/Iran during four months leading up to July 2019. Based on the research theoretical framework, the salesmen's emotional intelligence is an independent variable, their demographic characteristics are a mediating variable, and in-person sales skills are a dependent variable. The data collection tool was Schering's standardized emotional intelligence questionnaire and Basir et al.'s standardized sales skills questionnaire which was distributed among the salesmen in the real environment of the commercial complexes. Data analysis was performed under two broad categories of descriptive and inferential statistics. Pearson's statistical test was used to determine the correlation between the variables and testing the research hypotheses. In addition, the partial correlation test was used to examine the moderating role of demographic variables on the relationship between salesmen's emotional intelligence and their sales skills. All statistical analysis was performed by using SPSS v.22.0. The research results show that there is a direct and significant relationship between all components of emotional intelligence (self-awareness, self-management, self-motivation, social awareness and social skills) and in-person sales skills. Furthermore, it was found that the demographic variables were not modulated relationship between emotional intelligence and in-person sales skills of salesmen.
\end{abstract}

Keywords: in-person sales, sales skills, emotional intelligence, salesmen, commercial complexes

\section{Introduction}

\subsection{Introduce the Problem}

Nowadays, the skills and performance of the sales force are considered as one of the major issues in today's competitive environment of businesses, because salesmen (salesforce) are the frontline of the customer relationship (Schwepker \& Ingram, 2016). On the other hand, evaluating market growth and its profitability as one of the main goals of all businesses depends on the sales volume (Almgren, 2014). The companies' success key in achieving greater sales and market share has consistently adapted to customers' expectations and needs from initial product design to its delivery. Such success can be accomplished when the principles and techniques of sales are implemented in an appropriate approach by a sales professional (Hassan, 2012).

Salesman performance can be seen as a function of individual, organizational, and environmental factors. Sales skills are considered as an affecting individual factor in salesman performance. The importance of sales skills is that the salesmen need some skills which enable them to have effective communication with customers, to identify and meet their needs and desires (Verbeke et al., 2011).

'Emotional intelligence' (EI) is a relatively new and growing area of investigation that has received an enormous amount of attention and popularity in various academic and non-academic circles during the last two decades (Chopra \& Kanji, 2010). Emotional intelligence is one of the most highly used psychological terms in popular nomenclature, yet its construct, divergent and predictive validities are contentiously debated. Despite this debate, the EI constructs are composed of a set of emotional abilities - recognizing emotional states in the self and others, using emotions to guide thought and behavior, understanding how emotions shape behavior, and emotion 
regulation - that undoubtedly influence important social and personal outcomes (Hogeveen et al., 2016).

According to this fact that retailers are facing a variety of customers' issues and tastes, they increasingly need to develop relationships with customers to attract them and succeed in their business. Therefore, the present study is aimed at investigating the relationship between salesmen's emotional intelligence and their in-person sales skills. Thus, an extensive literature review is done with a focus on sales skills, sales performance, and emotional intelligence. In the following, the study conceptual model and its hypotheses are presented. In addition, the data analysis and results are provided. Finally, the results and suggestions for future research are discussed.

\subsection{Theoretical Basics and Research Background}

As cited earlier, sales skills are considered as one of the most effective individual factors in salesmen performance (Talukder \& Jan, 2017). Although Forbes magazine reports that more than half of the people working in sales lack key skills; however, professional salespeople can provide a competitive advantage for their company or business by improving long-term relationships with customers that will ultimately improve their performance. Establishing long-term relationships with customers is one of the key goals of companies, both at the micro and macro level (Yeo et al., 2019; Evanschitzky et al., 2012). Some benefits of these type long-term relationships are increased customer satisfaction and loyalty, which ultimately leads to increased sales volume and its profits. For this reason, companies and enterprises have turned to a customer-centric strategy for survival and growth in the competition (Alrubaiee \& Al-Nazer, 2010).

Sales skills are defined as the learned skills by individuals to perform the essential tasks of a sales job which include four distinct sections: sales closing skills, interpersonal skills, technical skills and marketing skills. According to these interpretations, the influential factor that has been few studies on the sales skills and ultimately the performance of the sales force is the issue of the "emotional intelligence" of the salesmen or sales force (Singh et al., 2015).

Emotional intelligence is a relatively new concept that has attracted the attention of many researchers. Mayer and Salovey (1999) believe that: "Emotional intelligence is the ability to monitor one's own and others' feelings and emotions, to discriminate among them and to use this information to guide one's thinking and actions" (Cherniss, 2010). In fact, the concept of emotional intelligence is a multifactorial domain of social skills and competencies that affects one's ability to recognize and manage emotion, problem-solving, and adaptation. This effectively adapts a person to life's needs, pressures, and challenges (Chopra \& Kanji, 2010). Emotional intelligence consists of four components: self-skill, others-skill, awareness, and action. According to Daniel Goleman (1998) explains that emotional intelligence consists of four fundamental capabilities: self-awareness, self-management, social awareness, and social skill (Ugoani et al., 2015).

Given the widespread consumer-salesman relationship with retail as well as the high impact of seller behavior in the buyer decision making, understanding the importance of the relationship between salesmen's emotional intelligence and sales skills in in-person sales is considered to be the most important issue of the present study; because it seems that this issue strongly and directly affects sales performance. Therefore, the researcher in the present study intends to study the relationship between salesmen's emotional intelligence and their sales skills in in-person sales.

It is expected that the results of this study, in addition to further enriching the scientific research in this field, can be effective in enhancing the sales skills of salesmen in companies and micro-businesses, improving profitability and business performance. Figure 1 shows the research theoretical framework. 


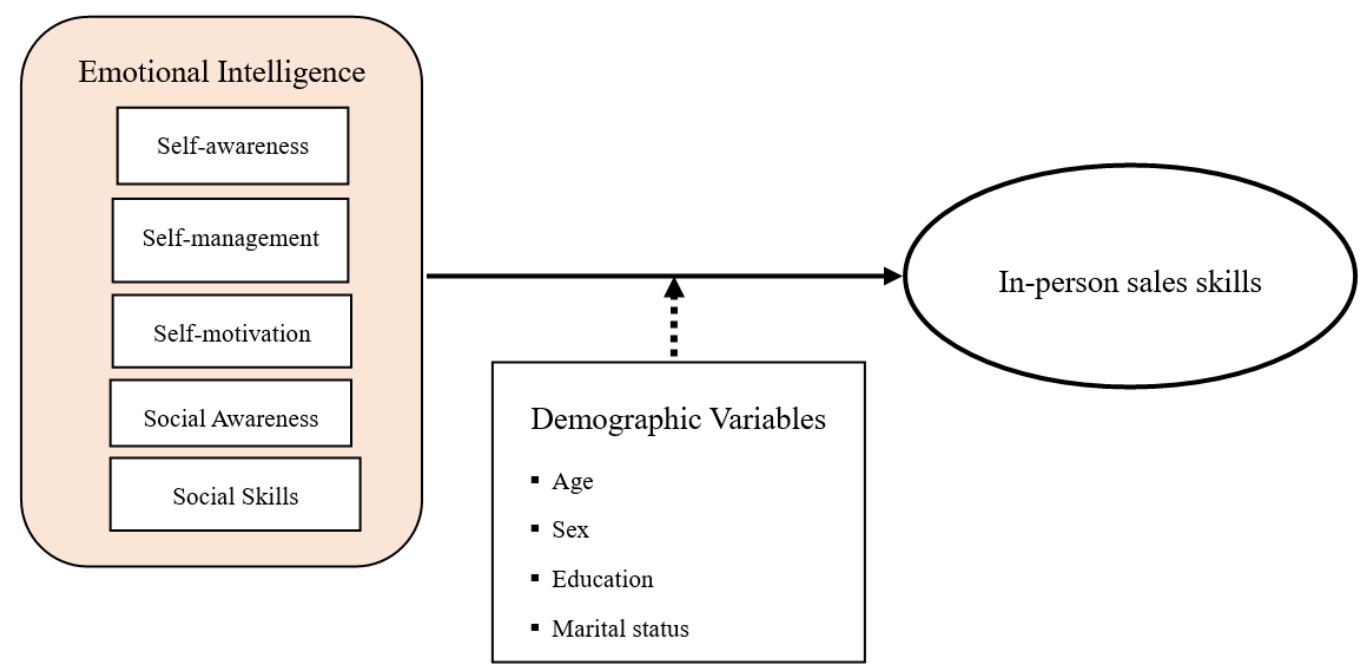

Figure 1. Theoretical framework (Wisker \& Poulis, 2015)

\subsection{Relevant Studies}

Shaban and Yadav (2018) explained the impact of emotional intelligence on sales performance among Indian salesmen. Research primary and secondary data were collected to provide a comprehensive analysis of various Indian car companies. Primary data were mostly based on gathering comprehensive data from primary sources such as an opinion poll, human resource management interviews, and so on. Furthermore, secondary data were also collected through the distribution of questionnaires by mail, e-mail, telephone, internet surveys, newspapers, trade magazines, and publications, etc. The results show that emotional intelligence has a direct and positive impact on sales skills and sales performance.

Delpechitre and Beeler (2018) described how salesperson's emotional intelligence (EI) influences salesperson behaviors (i.e., emotional labor strategies) and the influence these behavioral strategies have on customers' outcomes. The study develops a conceptual model using past literature and test hypotheses using a salesperson-prospective customer dyadic sample. To participate in the study, 224 salespeople and their potential customers were recruited from three different companies. The results reveal the importance of conceptualizing the dimensionality of a salesperson's EI ability, as different dimensions impact customer outcomes differently. Additionally, the importance of salesperson's authentic emotional labor strategies is highlighted.

AlDosiry et al. (2016) investigated the relationship between emotional intelligence (EI) and Total Sales Performance (TSP), and whether EI contributes to predicting the performance of sales professionals in Kuwait. The sample was 218 sales professionals working for 24 different car dealerships. An ability model of EI was measured using the Assessing Emotions Scale (AES) developed by Schutte et al. (1998) and its Arabic version. The trait model of EI was assessed using the Effective Intelligence Scale (EIS). The findings showed a negative, but weak correlation between TSP and the AES and all its subscales. No correlation was found between TSP and the EIS. A weak positive correlation existed between Objective Sales Performance and each of total EIS, Accuracy, and Patience subscales.

Selma et al. (2016) explored the linkages among emotional intelligence, relational selling behavior, and salesperson performance. Two data sets from business-to-business salespeople in various industrial and service sectors were analyzed with structural equation modeling. Mediation hypotheses were cross-validated through a bootstrapping approach with bias-corrected confidence estimates. The study offers new insights to sales and marketing managers on how individual capabilities (such as emotional intelligence) can be transformed into high sales performance. The results suggest that two focal types of selling behaviors - namely, adaptive selling and customer-oriented selling-fully mediate the positive relationship between emotional intelligence and salesperson performance.

Wisker and Poulis (2015) examined the impact of emotional intelligence on sales performance. They hypothesized that the impact of emotional intelligence on sales performance was mediated by adaptive selling behaviour. Data were collected from salespeople in the financial industries in Malaysia via the WLEIS emotional intelligence scale and ADAPTS adaptive selling behaviour scale, and were quantitatively analysed using 
structural equation modelling (SEM). Results were in keeping with the model. Emotional intelligence was not found to impact sales performance directly. It impacted on sales performance through a mediating variable; adaptive selling behaviour.

\subsection{Research Hypotheses}

1) There is a significant relationship between salesmen's emotional intelligence and in-person sales skills.

2) Salesmen's demographic variables moderate the relationship between emotional intelligence and in-person sales skills.

\section{Method}

The present study is applied and descriptive research. Also, since the questionnaire is a tool for collecting research data, it is survey-correlation in terms of implementation method.

\subsection{Statistical Population and Sample}

The research statistical population includes all salesmen in famous shopping malls in the third Municipality district of Bandar Abbas city in Iran (City Center Shopping Mall, Star City Shopping Mall, South Star Shopping Mall and Zeytoon Shopping Mall). Due to the lack of complete information on the exact number of salesmen, the research statistical sample size was calculated based on Cochran sampling formula in an unlimited population of 384 people. The questionnaire was also randomly distributed among the salesmen by using the convenience sampling method.

\subsection{Data Gathering}

After collecting information about the demographic characteristics of salesmen (gender, age, education, marital status, work experience), the required data to test the hypotheses have been gathered by using the Siberia Schering's emotional intelligence questionnaire (1996) and Basir et al. (2010) sales skills questionnaire.

The Research Emotional Intelligence Questionnaire is a standardized version based on the prevailing cultural conditions in Iran and has 33 items. It measures the five components of self-awareness, self-control (management), self-motivation, social awareness, and social skills. The sales skills questionnaire also includes 17 items, in which respondents are asked to rate their skills as a professional salesperson (interpersonal skills, sales closing, technical and marketing) on a five-point Likert scale (Very poor: 1 to excellent: 5).

Table 2 shows the reliability of the questionnaires by calculating Cronbach's alpha coefficient. The results of Cronbach's alpha coefficient calculation for the whole questionnaire show a value of $82 \%$, which indicates the appropriate reliability of the research questionnaire.

Table 1. Cronbach's alpha coefficient

\begin{tabular}{lll}
\hline Components & Number of items & Cronbach's coefficient \\
\hline Self-awareness & 8 & 0.75 \\
Self-management & 7 & 0.60 \\
Self-motivation & 7 & 0.86 \\
Social Awareness & 6 & 0.88 \\
Social Skills & 5 & 0.85 \\
Interpersonal Skills & 5 & 0.89 \\
Sales Closing Skills & 3 & 0.82 \\
Technical Skills & 5 & 0.87 \\
Marketing Skills & 4 & 0.91 \\
\hline
\end{tabular}

\subsection{Measures and Covariates}

Data analysis was performed at two levels of descriptive and inferential statistics. In descriptive statistics, frequency, mean, standard deviation, skewness, kurtosis and one-sample t-test were calculated. At the inferential statistics level, Pearson's statistical test was used to determine the correlation between the variables and testing the research hypotheses. Also, the partial correlation test was used to examine the moderating role of demographic variables on the relationship between emotional intelligence of salesmen and their sales skills.

\section{Results}

\subsection{Descriptive Findings}

1) Most salesmen are men (70\%) in the age range of between $31-40$ years. Also, $65 \%$ of salesmen are married 
and $49 \%$ of them have a bachelor's degree. Finally, descriptive findings show that $31 \%$ of salesmen have work experience between 6-8 years. Table 2 represents the demographic profile of the salespeople.

Table 2. Descriptive findings of preliminary research questionnaire

\begin{tabular}{lll}
\hline Variables & Components & Frequency \\
\hline Gender & Female & $70 \%$ \\
Marital status & Male & $30 \%$ \\
Age & Single & $65 \%$ \\
& Married & $35 \%$ \\
& $18-25$ & $28 \%$ \\
& $26-33$ & $24 \%$ \\
Education & $34-41$ & $30 \%$ \\
& $42-50$ & $14 \%$ \\
& Over 50 & $4 \%$ \\
Work Experience & Lower Level Diploma \& Diploma & $26 \%$ \\
& Associate Degree & $20 \%$ \\
& Bachelor & $49 \%$ \\
& Master \& Ph.D. & $5 \%$ \\
& Less than 2 years & $15 \%$ \\
& 2 to 4 years & $16 \%$ \\
& 4 to 6 years & $18 \%$ \\
& 6 to 8 years & $31 \%$ \\
& More than 8 years & $20 \%$ \\
\hline
\end{tabular}

2) In evaluating the salesmen emotional intelligence, it was found out that the emotional intelligence of the salespeople is at an average level (36\%). The obtained results show that the lowest level of salesmen's emotional intelligence is $28 \%$ (very low and low) and its highest level is $36 \%$ (high and very high). The details of salespersons' emotional intelligence represent that the salesmen's self-awareness is at a high level. The level of self-management, social awareness, and social skills is moderate, and finally, the level of self-motivation is evaluated at a low level. Table 3 shows the statistical findings of salesmen's emotional intelligence.

Table 3. Salesmen emotional intelligence statistical findings

\begin{tabular}{llllll}
\hline Salesmen Emotional Intelligence & Very Low & Low & Moderate & High & Very High \\
\hline Self-awareness & $9 \%$ & $14 \%$ & $23 \%$ & $31 \%$ & $23 \%$ \\
Self-management & $8 \%$ & $16 \%$ & $45 \%$ & $20 \%$ & $11 \%$ \\
Self-motivation & $26 \%$ & $34 \%$ & $21 \%$ & $14 \%$ & $5 \%$ \\
Social Awareness & $8 \%$ & $15 \%$ & $44 \%$ & $18 \%$ & $15 \%$ \\
Social Skills & $3 \%$ & $6 \%$ & $49 \%$ & $29 \%$ & $13 \%$ \\
Total Average & $11 \%$ & $17 \%$ & $36 \%$ & $23 \%$ & $13 \%$ \\
\hline
\end{tabular}

3) The descriptive findings show that salesmen's sales skills are at a desirable level (38\%, high and very high). The results show that the low level of sales skills is $27 \%$ (very low and low) and moderate level is $35 \%$. The details of sales skills indicate that the salesmen's interpersonal and technical skills are at a moderate level (48\% \& 42\%). The salesmen's "sales closing skills" is at a desirable level (high and very high: 60\%). Finally, it was found that among sales skills, marketing skills are considered undesirable. Table 4 shows the statistical findings of salesmen's sales skills.

Table 4. Salesmen's sales skills statistical findings

\begin{tabular}{llllll}
\hline Sales Skills & Very Low & Low & Moderate & High & Very High \\
\hline Interpersonal & $10 \%$ & $14 \%$ & $48 \%$ & $19 \%$ & $9 \%$ \\
Sales Closing & $5 \%$ & $10 \%$ & $25 \%$ & $38 \%$ & $22 \%$ \\
Technical & $8 \%$ & $13 \%$ & $42 \%$ & $16 \%$ & $21 \%$ \\
Marketing & $13 \%$ & $33 \%$ & $25 \%$ & $16 \%$ & $13 \%$ \\
Total Average & $9 \%$ & $18 \%$ & $35 \%$ & $22 \%$ & $16 \%$ \\
\hline
\end{tabular}


In addition, Table 5 and Table 6, respectively, show the descriptive indicators of the research variables and the results of the Kolmogorov-Smirnov test. The results show the normal distribution of the collected data.

Table 5. Descriptive indices of research variables

\begin{tabular}{lllll}
\hline Variables & Mean & Standard Deviation & Skew & Kurtosis \\
\hline Self-awareness & 3.693 & 0.858 & 0.120 & -0.953 \\
Self-management & 3.450 & 0.733 & 0.060 & 0.115 \\
Self-motivation & 3.593 & 0.778 & -0.047 & -0.928 \\
Social Awareness & 3.490 & 0.637 & 0.273 & -0.215 \\
Social Skills & 3.510 & 0.719 & -0.425 & -0.215 \\
Interpersonal Skills & 3.590 & 0.619 & 0.009 & -0.267 \\
Sales Closing Skills & 3.740 & 0.658 & 0.192 & -0.519 \\
Technical Skills & 3.620 & 0.53 & 0.19 & -0.03 \\
Marketing Skills & 3.470 & 0.740 & -0.58 & 0.89 \\
\hline
\end{tabular}

Table 6. Kolmogorov Smirnov test results

\begin{tabular}{llll}
\hline Variables & Test Statistic & df & Significance Level \\
\hline Self-awareness & 1.020 & 383 & 0.117 \\
Self-management & 1.060 & 383 & 0.147 \\
Self-motivation & 0.904 & 381 & 0.473 \\
Social Awareness & 1.472 & 382 & 0.081 \\
Social Skills & 1.835 & 382 & 0.062 \\
Interpersonal Skills & 1.384 & 383 & 0.094 \\
Sales Closing Skills & 1.490 & 383 & 0.078 \\
Technical Skills & 1.423 & 383 & 0.075 \\
Marketing Skills & 1.472 & 383 & 0.081 \\
\hline
\end{tabular}

\subsection{Data Analysis Findings}

This section presents the inferential data analysis. At first, dimensions of the emotional intelligence correlation matrix (Table 7) and salesmen demographic variables (Table 8) are drawn and then the research hypotheses are examined. The results show that there is a strong correlation (significant) between emotional intelligence dimensions at $95 \%$ confidence level; in other words, there is a convergence between all dimensions of emotional intelligence; that is, by increasing the dimensions of emotional intelligence, it can be improved among salesmen. On the other hand, the correlation matrix among the components of the salesmen demographic variables represents that there is a positive and significant correlation among all dimensions of the demographic variables.

Table 7. Emotional intelligence correlation matrix

\begin{tabular}{llllll}
\hline Variables & Self-awareness & Self-management & Self-motivation & Social Awareness & Social Skills \\
\hline Self-awareness & 1 & 0.787 & 0.776 & 0.835 & 0.832 \\
p-value & & 0.002 & 0.001 & 0.001 & 0.001 \\
Self-management & 0.787 & 1 & 0.768 & 0.751 & 0.685 \\
p-value & 0.002 & & 0.003 & 0.001 & 0.004 \\
Self-motivation & 0.776 & 0.768 & 1 & 0.807 & 0.768 \\
p-value & 0.002 & 0.001 & & 0.000 & 0.001 \\
Social Awareness & 0.835 & 0.751 & 0.807 & 1 & 0.782 \\
p-value & 0.002 & 0.001 & 0.000 & & 0.003 \\
Social Skills & 0.832 & 0.685 & 0.768 & 0.782 & 1 \\
p-value & 0.000 & 0.002 & 0.001 & 0.001 & 0.987 \\
Emotional Intelligence & 0.933 & 0.872 & 0.911 & 0.923 & 0.000 \\
p-value & 0.002 & 0.001 & 0.000 & 0.001 & \\
\hline
\end{tabular}


Table 8. Demographic factors correlation matrix

\begin{tabular}{lllll}
\hline Variables & Age & Gender & Education & Marital Status \\
\hline Age p-value & 1 & 0.706 & 0.609 & 0.769 \\
& & 0.001 & 0.001 & 0.001 \\
Gender p-value & 0.706 & 1 & 0.818 & 0.863 \\
& 0.002 & & 0.000 & 0.001 \\
Education p-value & 0.609 & 0.818 & 1 & 0.741 \\
Marital Status p-value & 0.002 & 0.000 & & 0.000 \\
& 0.732 & 0.699 & 0.846 & 1 \\
Demographic Factors p-value & 0.002 & 0.001 & 0.000 & \\
& 0.875 & 0.934 & 0.886 & 0.846 \\
& 0.001 & 0.000 & 0.000 & 0.001 \\
\hline
\end{tabular}

\subsection{Hypothesis Test Results}

1) There is a significant relationship between salesmen's emotional intelligence and in-person sales skills.

Table 9 shows the results of calculating the Pearson's correlation coefficient between salesmen emotional intelligence and their sales skills. The obtained results confirm all coefficients at $95 \%$ confidence level. As a result, it can be said that as the value of one variable increases or decreases, the other one is also increases or decreases. In other words, there is a direct and significant relationship between salesmen's emotional intelligence and their in-person sales skills. That means the in-person sales skills of salesmen are enhanced by reinforcing the emotional intelligence components. The correlation coefficient between the variables also indicates that the intensity of the relationship between self-management and in-person sales skills is higher than the other variables.

Table 9. Correlation test between salesmen emotional intelligence and in-person sales skills

\begin{tabular}{lll}
\hline Variables & Pearson correlation coefficient $\mathrm{R}^{2}$ & P-Value \\
\hline Self-awareness \& In-person Sales Skills & 0.53 & 0.000 \\
Self-management \& In-person Sales Skills & 0.65 & 0.003 \\
Self-motivation \& In-person Sales Skills & 0.57 & 0.000 \\
Social Awareness \& In-person Sales Skills & 0.58 & 0.001 \\
Social Skills \& In-person Sales Skills & 0.56 & 0.000 \\
\hline
\end{tabular}

2) Salesmen's demographic variables moderate the relationship between emotional intelligence and in-person sales skills.

Table 10 shows the results of the partial correlation test. Due to the significance level of $99 \%$, it is can be seen that all four demographic variables (gender, education, age, and marital status) have less impact on the relationship between emotional intelligence and in-person sales skills, and this relationship has no much changed by the moderating role of demographic variables. Therefore, this main hypothesis and its sub-hypotheses are not confirmed. As a result, it can be stated that demographic variables on the relationship between emotional intelligence and in-person sales skills do not play a significant moderating role.

Table 10. Partial correlation test

\begin{tabular}{llll}
\hline $\begin{array}{l}\text { Relationship between Main Research } \\
\text { Variables }\end{array}$ & $\begin{array}{l}\text { Demographic } \\
\text { Variables }\end{array}$ & $\begin{array}{l}\text { Impact Intensity without } \\
\text { Moderator }\end{array}$ & $\begin{array}{l}\text { Impact Intensity with } \\
\text { Moderator }\end{array}$ \\
\hline $\begin{array}{l}\text { Relationship between Salesmen Emotional } \\
\text { Intelligence and In-person Sales Skills }\end{array}$ & Gender & $0.846^{* *}$ & $0.849^{* *}$ \\
& Education & & $0.839^{* *}$ \\
& Age & & $0.844^{* *}$ \\
& Marital Status & & $0.849^{* *}$ \\
\hline
\end{tabular}

\section{Discussion}

The results of the present research are in full agreement with the results of previous researchers' study such as Shaban and Yadav (2018), Delpechitre and Beeler (2018) and Selma et al. (2016), those who have been 
confirmed in their studies that there is a significant relationship between salesmen's emotional intelligence and their in-person sales skills. However, there are few researchers, such as AlDosiry (2016), who find that there is no significant relationship between salesmen's emotional intelligence and their in-person sales skills. Furthermore, Wisker and Poulis (2015) have found out that there is an indirect relationship between emotional intelligence and salesmen in-person sales skills, although this result has not been confirmed in the present study. According to the study results, the following is the suggestions given to the salesmen or sales forces:

1) There is a significant relationship between salesman self-awareness and sales skills.

The research findings show that the level of self-awareness of salesmen is high. So, it can be concluded that salesmen understand very well their values and goals. In other words, salesmen highly aware of self-emotions. However, the following is suggestions given to salesmen for a better understanding and improving self-awareness:

- Writing Plans and Priorities: One of the best ways to increase self-awareness is to write Priorities and future goals. Written plans help people to assess their future results. In this way, it is possible to evaluate and record the positive and negative points of an individual's personality. This helps us to improve our personality weaknesses and strengthen our strengths.

- Using Psychological Tests: Salesmen can better understand their personality and characteristics by using psychological tests such as Myers-Briggs Type Indicator (MBTI), NEO Personality Inventory-Revised (NEO PI-R), and DISC Profiler. Also, they can try to enhance their self-awareness by attending various seminars and training courses held by educational institutions in Bandar Abbas city.

- Giving regular feedback at work: Salesmen can implement a system in their own business that their customers be able to send valuable and constructive feedback to them. This leads to a better and more realistic understanding of salesmen's strengths and weaknesses.

2) There is a significant relationship between salesmen self-management and sales skills.

Self-management plays an important role in creating power for the salesperson to manage sales behavior and enhance sales skills in order to improve performance and business profitability. The research findings show that the salesmen self-management rate, as one of the emotional intelligence components is at the moderate level. Self-management capabilities indicate a person's adaptability, initiative, desire to succeed, work ethics, self-confidence, flexibility and comprehensive approach to everything. Therefore, the following is the suggestions given to the salesmen for having better self-management:

- Creating appropriate infrastructures to foster creativity and innovation in sales and business.

- Attending self-management courses training to balance thought and skill.

- Enhancing close cooperation and communication between salesmen and customers, as well as, salesmen with each other to exchange ideas.

- Creating strong and appropriate information networks in salesmen's communication channels with customers and other salesmen.

3) There is a significant relationship between salesmen self-motivation and sales skills.

Self-motivation is, in its simplest form, the force that drives a person to do things. It's the drive a person has to work toward his goals, to put effort into self-development, and to achieve personal fulfillment. The research findings show that salesmen's self-motivation rate and optimism about the future is in an unfavorable situation. Therefore, the following is the suggestions given for salesmen to improve self-motivation:

- It is important to understand what motivates us because by knowing it, people will be able to focus their efforts on achieving the same goals and organize their work. Therefore, attending motivational training courses, as well as creating conditions for a person to better understand their motivators, can lead to self-motivation.

- Hoping for better tomorrows can reinforce self-motivation. Therefore, it is important to provide opportunities for salesmen to be always hopeful for having a better future in business and make efforts that will strengthen and maintain their morale.

4) There is a significant relationship between the salesmen social awareness and sales skills.

Social awareness is the ability to comprehend and appropriately react to both broad problems of society and interpersonal struggles. This means that being socially aware relates to being aware of your environment, what's around you, as well as being able to accurately interpret the emotions of people with whom you interact. The 
research findings show that salesmen social awareness rate is at moderate level. The following is the suggestions given for salesmen to improve social awareness:

- Be an active listener and try to understand the needs and capabilities of another person.

- Give others the opportunity to express their emotions easily and try to understand others at different times.

- Express our emotions carefully and accurately to give empathy so that the other person can feel at ease.

- Accept people with their differences and avoid judging others.

- Don't blame and pity others when they empathize with you. Also, do not assume others problems small and worthless.

5) There is a significant relationship between the salesmen social skills and sales skills.

Research findings show that the careful controlling of emotions, responsiveness, teamwork and ability to make clear communication with customers and colleagues is at a moderate level among salespeople. The research findings show that salesmen level of self-control (emotion control), appropriate response, teamwork, ability to talk, transparent communication with customers and colleagues among is at the moderate level. The following is the suggestions given for salesmen to improve social skills:

- Improving direct communication skills with customers, partners, competitors, and etc.

- Respect customer's opinions, feelings, and freedom of expression.

- Be fair and non-discriminatory behaviour with customers.

- Informing customers about business changes and developments.

\section{References}

AlDosiry, K. S. (2016). Relationships between emotional intelligence and sales performance in Kuwait. Revista de Psicología del Trabajo y de las Organizaciones, 32(1), 39-45. https://doi.org/10.1016/j.rpto.2015.09.002

Almgren, K. (2014). The Four Factors for Targeting an Attractive Market. International Journal of Humanities and Social Science, 4(9), 71-76, http://www.ijhssnet.com/journals/Vol_4_No_9_1_July_2014/9.pdf

Alrubaiee, L., \& Al-Nazer, N. (2010). Investigate the Impact of Relationship Marketing Orientation on Customer Loyalty: The Customer's Perspective. International Journal of Marketing Studies, 2(1), 155-171. https://doi.org/10.5539/ijms.v2n1p155

Basir, M. S., Ahmad, S. Z., \& Kitchen, P. J. (2010). The Relationship between Sales Skills and Salesperson Performance: An Empirical Study in the Malaysia Telecommunications Company. International Journal of Management and Marketing Research, 3(1), 51-73. https://ssrn.com/abstract=1668838

Cherniss, C. (2010). Emotional Intelligence: Toward Clarification of a Concept. Industrial and Organizational Psychology, 3, 110-126. https://doi.org/10.1111/j.1754-9434.2010.01231.x

Chopra, P., \& Kanji, G. (2010). Emotional intelligence: A catalyst for inspirational leadership and management excellence. Total Quality Management \& Business Excellence, 21(10), 971-1004. https://doi.org/10.1080/14783363.2010.487704

Delpechitre, D., \& Beeler, L. (2018). Faking it: salesperson emotional intelligence's influence on emotional labor strategies and customer outcomes. Journal of Business \& Industrial Marketing, 33(1), 53-71. https://doi.org/10.1108/JBIM-08-2016-0170

Evanschitzky, H., Sharma, A., \& Prykop, C. (2012). The Role of the Sales Employee in Securing Customer Satisfaction. European Journal of Marketing, 46(3/4), 489-508. https://doi.org/10.1108/03090561211202576

Hassan, A. (2012). The Value Proposition Concept in Marketing: How Customers Perceive the Value Delivered by Firms-A Study of Customer Perspectives on Supermarkets in Southampton in the United Kingdom. International Journal of Marketing Studies, 4(3), 67-87. https://doi.org/10.5539/ijms.v4n3p68

Hogeveen, J., Salvi, C., \& Grafman, J. (2016). 'Emotional Intelligence': Lessons from Lesions. Trends in Neurosciences, 39(10), 694-705. https://doi.org/10.1016/j.tins.2016.08.007

Schwepker, C., \& Ingram, T. (2016). Ethical leadership in the salesforce: effects on salesperson customer orientation, commitment to customer value and job stress. Journal of Business \& Industrial Marketing, 31(7), 914-927. https://doi.org/10.1108/JBIM-07-2015-0136 
Selma, K. M. et al. (2016). Clarifying the influence of emotional intelligence on salesperson performance. Journal of Business \& Industrial Marketing, 31(7), 877-888. https://doi.org/10.1108/JBIM-09-2015-0168

Shaban, M., \& Yadav, R. (2018). Impact of Emotional Intelligence on Sales Performance. IOSR Journal of Business and Management (IOSR-JBM), 20(4), 8-13.

Singh, V. L., Manrai, A., \& Manrai, L. (2015). Sales training: a state of the art and contemporary review, Journal of Economics. Finance and Administrative Science, 20(38), 54-71. https://doi.org/10.1016/j.jefas.2015.01.001

Talukder, K., \& Jan, M. (2017). Factors Influencing Sales People's Performance: A Study of Mobile Service Providers in Bangladesh. Academy of Marketing Studies Journal, 21(2), 1-20.

Ugoani, J., Amu, C., \& Emenike, K. (2015). Dimensions of Emotional Intelligence and Transformational Leadership: A Correlation Analysis. Independent Journal of Management \& Production, 6(2), 563-584. https://doi.org/10.14807/ijmp.v6i2.278

Verbeke, W., Dietz, B., \& Verwaal, E. (2011). Drivers of sales performance: a contemporary meta-analysis. Have salespeople become knowledge brokers? Journal of the Academy of Marketing Science, 39, 407-428. https://doi.org/10.1007/s11747-010-0211-8

Wisker, Z. L., \& Poulis, A. (2015). Emotional Intelligence and Sales Performance. A Myth or Reallity? International Journal of Business and Society, 16(2), 185-200. https://doi.org/10.33736/ijbs.563.2015

Yeo, C., Hur, C., \& Ji, S. (2019). The Customer Orientation of Salesperson for Performance in Korean Market Case: A Relationship between Customer Orientation and Adaptive Selling. Sustainability, 11, 6115. https://doi.org/10.3390/su11216115

\section{Copyrights}

Copyright for this article is retained by the author, with first publication rights granted to the journal.

This is an open-access article distributed under the terms and conditions of the Creative Commons Attribution license (http://creativecommons.org/licenses/by/4.0/). 